Grasas y Aceites

Vol. 50. Fasc. 2 (1999), 141-152

\title{
REVISIÓN
}

\section{Consumo de café y colesterol sérico}

\section{Por M.G. Montero Rodríguez, M.A. Talón Marqués y F.J. Sánchez-Muniz *}

* Departamento de Nutrición y Bromatología I (Nutrición). Sección Lípidos. Facultad de Farmacia.

Universidad Complutense. 28040 - Madrid. TIf.: 91-3941828 Fax: 91-3941732

e-mail: frasan@eucmax.sim.ucm.es

\section{RESUMEN}

\section{Consumo de café y colesterol sérico.}

Se revisan en primer lugar aspectos sobre los tipos y variedades de café de importancia comercial, con especial mención de la composición química del grano verde y del tostado; y particularmente de la fracción lipídica. En segundo lugar se analiza la posible relación del consumo de café y algunos factores de riesgo de enfermedades cardiovasculares, con especial interés en el estudio del efecto de los diferentes tipos de café, sus formas de preparación y la presencia de los diterpenos cafestol y kahweol sobre la concentración de los lípidos y lipoproteínas séricas de los consumidores. Entre otros aspectos se señala la pérdida del efecto hipercolesterolemiante de las preparaciones hervidas cuando son filtradas.

PALABRAS-CLAVE: Café - Cafestol - Colesterol - Composición química - Kahweol - Lipoproteína - Revisión (artículo).

\section{SUMMARY}

Coffee consumption and serum cholesterol.

Different topics related to the kind and variety of coffee with commercial value, specially of the chemical composition of the green and toasted grain and particularly of the composition of the lipid fraction, are firstly revised. Secondly, the possible relationship between coffee consumption and some risk factors of cardiovascular diseases are also analysed, searching for the effect of different kinds of coffee, ways of preparation and the presence of the cafestol and kahweol diterpens on the level of serum lipids and lipoproteins on consumers. Among other conclusions, the loss of the hypercholesterolemic effect when the boiled preparations are filtered is noted.

KEY-WORDS: Cafestol - Chemical composition - Cholesterol Cofee - Kahweol - Lipoprotein - Review (article).

\section{INTRODUCCIÓN}

El café es una bebida preparada mediante la extracción de la materia soluble en agua caliente de los granos tostados y molidos que proceden del fruto de un arbusto tropical llamado cafeto (Desrosier, 1987).
Las primeras plantas de cafeto de las que se tiene conocimiento (de la especie arábica) son originarias de Etiopía, donde crecía de forma silvestre y los nativos ya utilizaban sus semillas.

La leyenda cuenta que Kaldi, un joven pastor, notó que sus cabras se volvían más inquietas después de morder las hojas y los frutos de este arbusto; y se dice que el pastor cuando saboreó el grano, no pudo conciliar el sueño esa noche. El lugar de Kaffa (de aquí proviene su nombre) parece ser la zona etíope donde se probó el café por primera vez. Los árabes llevaron el arbusto a Yemen al parecer en el año 575, y en el siglo XIII se inició la costumbre de tostar el grano (De la Mota, 1991). Por mucho tiempo la explotación del café estuvo limitada a esa zona, principalmente Arabia y estaba prohibida la exportación de las semillas que no hubieran sido procesadas previamente. Fueron unos peregrinos de la Meca los que lograron sacar ocultas entre sus ropas las primeras semillas llevadas a la India. Durante el siglo XVII el café se introdujo en los países europeos y no tardó en hacerse popular en lugares como las salas de café (Desrosier, 1987; De la Mota, 1991). En 1658 los holandeses comenzaron el cultivo a gran escala en Sri Lanka (Ceilán) con plantas traídas desde la India y en 1696 se iniciaron las plantaciones en Java, de donde salió el primer envío comercial hacia la ciudad de Amsterdam. En 1707 el Jardín Botánico de dicha ciudad holandesa recibió las primeras plantas de café, las cuales eran centro de atención por las leyendas que precedían a este fruto exótico, de cultivo limitado y alto precio, ya que los musulmanes lo utilizaban como estimulante para mantenerse despiertos en las mezquitas y los turcos reconocian la propiedad estimulante y medicinal de este producto. El cultivo del cafeto en las Indias Occidentales se inició entre 1715 y 1750 por parte de los franceses, ingleses y españoles, pero no fue hasta después de 1800 cuando se empezó a cultivar en México y Centro América y no fue hasta después de la Segunda Guerra Mundial cuando se inició el 
cultivo comercial en Africa. En la actualidad, los europeos son grandes consumidores de café (Debry, 1994). El café filtrado e instantáneo soluble es común en los países del oeste europeo. En los países cercanos al Mar Mediterráneo el café expreso, moka y el Turco/griego son más populares. En cambio, en las naciones escandinavas se utiliza el café obtenido al poner los granos en agua hirviente y decantado sin filtrar, aunque este estilo está declinando.

El cafeto es una planta dicotiledónea que pertenece a la familia de las rubiáceas. El arbusto se cultiva principalmente entre el Trópico de Cáncer y Capricornio, a altitudes entre los 610 y 1830 m sobre el nivel del mar, con temperaturas cercanas a los $21^{\circ} \mathrm{C}$ y precipitaciones anuales de alrededor de $1.27 \mathrm{~m}^{3}$.

En el interior del fruto se encuentran dos semillas rodeadas de una pulpa amarillenta, éstas constituyen los llamados granos de café. Inicialmente son verdes, después se tornan amarillos y terminan adquiriendo un color rojo en su madurez. Las semillas están cubiertas por una piel semitransparente llamada epidermis plateada, y ésta a su vez por una cáscara denominada pergamino. (Fig. 1).

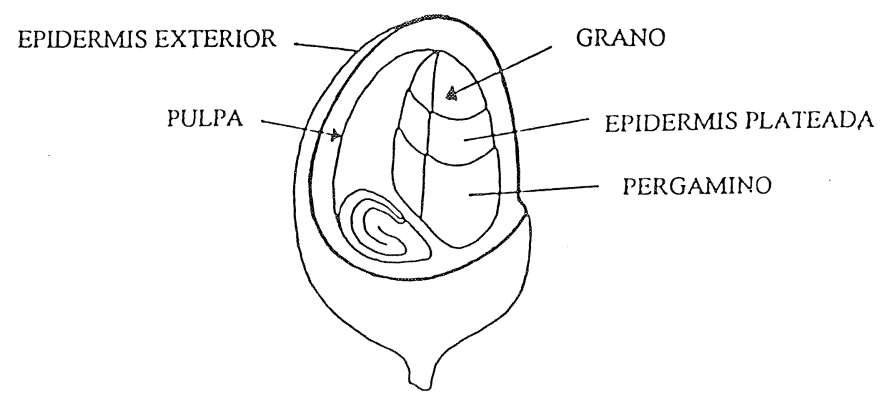

Figura 1

Esquema de las partes de la "cereza" del café

Bajo el nombre genérico de Coffea existen más de sesenta especies diferentes, de las cuales sólo tres tienen importancia comercial: Coffea arabica, Coffea robusta y Coffea liberica, las cuales se comentan a continuación.

\section{Coffea arabica}

Es originaria de Etiopía y por tanto la variedad más conocida y extendida y de su cultivo se obtiene alrededor del $80 \%$ de la producción mundial de café, dada su excelente calidad. El arbusto florece al tercer año, pudiéndose iniciar la producción un año después de dar flor y su rendimiento llega a alcanzar entre los $400 \mathrm{~g}$ y los $2 \mathrm{Kg}$. El crecimiento lento del cafeto en altitudes de 1220 a $1830 \mathrm{~m}$ produce cafés de mejor sabor, aunque la producción del arbusto sea menor y los granos más pequeños y más densos. Debido a esto, los cafés de zonas elevadas de Colombia, Venezuela, Costa Rica, Guatemala, México, etc., son de mejor sabor y más alto precio (Desrosier, 1987; De la Mota, 1991). Entre las variedades de este tipo de café más explotadas comercialmente se encuentran la variedad arábica (típica), y las Moka, Bourbon, Maragogype, Caturra y Mundo Novo. Tiene un menor porcentaje de cafeína que los otros tipos.

\section{Coffea canephora (robusta)}

Es originaria del Zaire (República Democrática del Congo) y se tiene conocimiento de ella desde 1898, cuando se generó interés por la posibilidad de cultivarla a bajas altitudes, contrariamente a lo ocurrido con la variedad arábica. Los arbustos son más grandes y dan una producción más abundante. También es más resistente a las enfermedades y sobrevive con poca cantidad de lluvia. Al segundo año de plantado florece y al año siguiente da la primera cosecha, su rendimiento promedio es de $600 \mathrm{~g}$ a $2,2 \mathrm{Kg}$. Entre las variedades más conocidas están: Konilloi, Niaouli y Congensis. De esta especie se obtienen cafés con sabores más fuertes y amargos (De la Mota, 1991).

\section{Coffea liberica}

Económicamente, no es tan importante como las especies anteriores, sin embargo es muy apreciada en los países escandinavos con variedades tales como la Indeniés o la Excelsa (De la Mota, 1991).

\section{COMPOSICIÓN QUIMIICA DE LAS DOS VARIEDADES MÁS CONSUMIDAS DE CAFÉ}

\subsection{Composición química del grano verde}

Desde el punto de vista químico, el café es, sin lugar a dudas, uno de los alimentos más complejos dentro de los de mayor consumo. Esto es debido a la variedad de compuestos químicos que contiene y a que todos ellos reaccionan e interaccionan entre sí en cada una de las etapas de procesamiento (Clifford y Willson, 1975; Clifford, 1985). Esta complejidad se halla incrementada por dos importantes problemas analíticos: los niveles extremadamente bajos de algunos de los componentes que poseen mayor significación sensorial, y las interacciones que dan lugar a la formación de polímeros de elevado peso molecular, a menudo muy difíciles de caracterizar estruc- 
turalmente, aun cuando pueden estar presentes hasta en un $50 \%$ en el café preparado.

La composición química del grano verde de café es claramente dependiente de las especies, y en menor medida, de otros factores tales como la altitud, la calidad del suelo, el grado de maduración, las prácticas agrícolas y las condiciones de almacenamiento (Stefanucci et al., 1979; Hui, 1992). La Tabla I presenta algunos datos sobre la composición porcentual de los granos de café verde para dos variedades de café. Dichas cifras aunque datan de 1975, suponen una información resumida bastante precisa de los datos disponibles, los cuales se han modificado escasamente desde entonces, si acaso para completar su composición hasta el $100 \%$ del peso de extracto seco al incluirse otros componentes identificados posteriormente.

Tabla I

Composición (\% extracto seco) de los granos de café verde y tostado para las variedades arábica y robusta, así como del café instantáneo

\begin{tabular}{lccccc}
\hline \multirow{2}{*}{ COMPONENTES } & \multicolumn{2}{c}{ CAFÉ ARABICA } & \multicolumn{2}{c}{ CAFÉ ROBUSTA } & CAFÉ INSTANTÁNEO \\
\cline { 2 - 5 } & Verde & Tostado & Verde & Tostado & \\
\hline Minerales & $3.0-4.2$ & $3.5-4.5$ & $4.0-4.5$ & $4.6-5.0$ & $9.0-10.0$ \\
Cafeína & $0.9-1.2$ & $\sim 1.0$ & $1.6-2.4$ & $\sim 2.0$ & $4.5-5.1$ \\
Trigonelina & $1.0-1.2$ & $0.5-1.0$ & $0.6-0.75$ & $0.3-0.6$ & - \\
Lípidos & $12.0-18.0$ & $14.5-20.0$ & $9.0-13.0$ & $11.0-16.0$ & $1.5-1.6$ \\
Acidos Clorogénicos totales & $5.5-8.0$ & $1.2-2.3$ & $7.0-10.0$ & $3.9-4.6$ & $5.2-7.4$ \\
Acidos Alifáticos & $1.5-2.0$ & $1.0-1.5$ & $1.5-2.0$ & $1.0-1.5$ & - \\
Oligosacáridos & $6.0-8.0$ & $0-3.5$ & $5.0-7.0$ & $0-3.5$ & $0.7-5.2$ \\
Polisacáridos totales & $50.0-55.0$ & $24.0-39.0$ & $37.0-47.0$ & - & $\sim 6.5$ \\
Aminoácidos & 2.0 & 0 & 2.0 & 0 & 0 \\
Proteínas & $11.0-13.0$ & $13.0-15.0$ & $11.0-13.0$ & $13.0-15.0$ & $16.0-21.0$ \\
Acidos Húmicos & - & $16.0-17.0$ & - & $16.0-17.0$ & 15.0 \\
\hline
\end{tabular}

Adaptado de Clifford (1975) y Vitzthum (1975).

Entre los hidratos de carbono más abundantes en los granos verdes de café están los polisacáridos, entre un $50-55 \%$ del extracto seco para la variedad arábica; mientras que el resto de los azúcares suponen alrededor del 7\% (Clifford y Willson, 1975). El café arábica contiene alrededor de un 3\% más hidratos de carbono que la variedad robusta, predominando los azúcares simples sobre los polisacáridos en el café arábica.

Entre los compuestos nitrogenados hay que distinguir: los alcaloides, la trigonelina, el ácido nicotínico, los aminoácidos y las proteínas (Clifford y Wilson, 1975). En el café verde se encuentra una fracción proteica soluble y otra insoluble, constituyendo la albúmina, la mitad del total de la primera fracción. El contenido de proteínas de estos granos se sitúa entre el $13-16 \%$ del extracto seco. En concordancia con los análisis de aminoácidos, al eliminar el porcentaje correspondiente de cafeína y trigonelina, se obtienen valores medios de proteínas del orden del $11,5 \%$ del extracto seco. La concentración de trigonelina encontrada en el café verde depende de la especie estudiada. El café arábica es el de mayor contenido (1\%), seguido del robusta $(0.7 \%$ ) y libérica $(0,25 \%)$. Los aminoácidos libres son probablemente los componentes más importantes relacionados con el aroma final del café preparado, y en menor medida del sabor. Con respecto al total de los compuestos nitrogenados, se encuentran en muy baja proporción $(0.15-0.25 \%$ ) y aunque se destruyen en un alto grado durante el tostado, son los principales responsables de la calidad del producto final. El contenido de cafeína varía ampliamente en los granos verdes de café, siendo un factor determinante para establecer diferencias entre especies. Así, el café arábica contiene un $1.2 \%$ de cafeína en su extracto seco, que puede llegar a ser el doble en el café robusta de algunos países africanos como Angola (Roffi et al., 1971; Charrier y Berthaud, 1975; Charrier, 1975; Clifford, 1975; Maier, 1981; Clarke y Macrae, 1989).

Los lípidos de los granos verdes de café están representados por los aceites y las ceras, éstas últimas en pequeña proporción. Los aceites se hallan principalmente en el endospermo, y la cera se localiza en las capas más externas del grano. El aceite 
contiene triglicéridos y una considerable proporción de otros componentes lipídicos, los cuales constituyen una característica importante de este aceite. Según diversos autores (Streuli, 1973; Clifford, 1975; Poisson, 1977; Maier, 1981; Clifford, 1985; Clarke y Macrae, 1989), existe un contenido muy diferente de lípidos en las distintas especies de café. Así, en el café arábica el contenido del aceite es de un $15 \%$ del extracto seco, mientras que en la variedad robusta es del $10 \%$. La cera del café, en el grano verde supone el $0,25 \%$ del extracto seco, lo que significa el $1,5-2,5 \%$ del total de los lípidos. Los diferentes componentes de los aceites del café se encuentran en las siguientes proporciones (\% lípidos totales): triglicéridos $75,2 \%$, ésteres de alcoholes diterpénicos y de ácidos grasos 18,5\%, alcoholes diterpénicos $0,4 \%$, esteroles esterificados y ácidos grasos esterificados $3,2 \%$, esteroles libres $2,2 \%$, tocoferoles 0,04-0,06\%, fosfátidos $0,1-0,5 \%$ y derivados de triptamina $0,6-1,0 \%$ (Maier, 1981). Estos compuestos han sido estudiados por numerosos autores, principalmente por el grupo de Kaufmann y Hamsagar (1962 a,b), Kaufmann y Schickel (1963) y Kaufmann y Sen Gupta $(1963,1964)$. No obstante, estas cifras derivan del aceite, el cual sólo ha podido ser extraído en el café arábica en una proporción cercana al $7 \%$. Datos procedentes de investigaciones posteriores sitúan el contenido de compuestos glicerídicos en el aceite del café entre 10-18\% (Clifford y Willson, 1985). Al Kahnal (1997) halló en los granos verdes del café arábica un $11,2 \%$ de un aceite parduzco y viscoso. Este aceite estaba constituido por un $0 ; 56 \%$ de compuestos polares, $4,5 \%$ de esteroles libres, $80,6 \%$ de triglicéridos, $5,0 \%$ de alcoholes terpénicos, $7,8 \%$ de esteroles esterificados, $0,5 \%$ de hidrocarburos y $12,0 \%$ de insaponificable. Esta última fracción resulta inusualmente elevada respecto a la encontrada en la mayoría de los aceites vegetales (Al Kahnal, 1997). Los resultados de este último autor coinciden en términos generales con los de otros muchos investigadores (Carisano y Gariboldi, 1964; Xábregas et al., 1971; Clifford y Willson, 1975; Clarke y Macrae, 1989; Al Kahnal, 1997). El contenido de ácidos grasos libres varía para diferentes muestras de café verde entre 0,50 y 1,89\% (Carisano y Gariboldi, 1964). Wajda y Walczyk (1978) señalaron una relación entre los porcentajes de ácidos grasos libres y el tiempo de almacenamiento del café, encontrándose grandes cantidades en aquellos granos conservados en condiciones de temperatura y humedad inadecuadas. Sólo en los casos de café molido o de café almacenado durante largo tiempo se puede esperar la existencia de cantidades significativas de lípidos peroxidados.

Respecto a los ácidos grasos totales, en el aceite extraído de los granos verdes predomina el ácido linoleico (37-43\%), seguido del ácido palmítico (3141\%) (Folstar et al., 1976). En el aceite existe un ligero predominio de los ácidos grasos insaturados ( $54 \%$ de ácido linoleico más oleico), mientras que en la cera abundan los ácidos grasos saturados (72\%). Además, los ácidos grasos saturados tienen preferencia por esterificarse con los diterpenos, mientras que los ácidos grasos insaturados se esterifican mayoritariamente con el glicerol (Kaufmann y Hamsagar, 1962a). Más recientemente, Al Kahnal (1997) ha señalado también el contenido mayoritario de ácido palmítico $(36 \%)$ y ácido linoleico $(40 \%)$ en el total de ácidos grasos presentes en el aceite extraído de las semillas verdes de la variedad arábica. Por otro lado, el porcentaje de ácido palmítico contenido en la fracción de triglicéridos es ligeramente superior, y el de ácido linoleico ligeramente inferior al hallado en el aceite total (Al Kahnal, 1997). No se han encontrado, en el análisis realizado de dichos ácidos grasos totales, diferencias significativas entre la variedad arábica y la robusta (Carisano y Gariboldi, 1964; Calzolari y Cerma, 1963; Chassevent et al., 1974).

La distribución posicional de los ácidos grasos en los triglicéridos del café revela que el ácido linoleico se localiza preferentemente en la posición sn-2, mientras que el ácido palmítico lo hace en la posición sn-1,3 (Al Kahnal, 1997). Así mismo, se ha encontrado una interesante similitud entre el aceite de palma y el aceite del café. En ambos aceites, la posición sn-1,3 es ocupada en su mayor parte por el ácido palmítico (58\% en el aceite de palma y $50 \%$ en el aceite del café) (Renaud et al., 1995). Este aspecto podría ser relevante, ya que es bien conocido que la digestión y absorción de los triglicéridos dietarios está enormemente influenciada por la distribución posicional de los ácidos grasos que contienen. Esta distribución posicional, condicionaría a su vez, los efectos potenciales del ácido palmítico sobre el metabolismo lipoproteico (Renaud et al., 1995; Innis et al., 1995).

Los diterpenos son estructuras químicas que se han identificado en el aceite del café y cuya unidad más simple (isopreno) es uno de los bloques constructivos favoritos en la naturaleza. Aunque pueden adoptar formas lineales, los de mayor importancia biológica son los cíclicos, como por ejemplo el retinol y el fitol. En el caso del café, varios alcoholes diterpénicos libres como Cafestol y Kahweól y algunos esterificados se han mostrado inductores de la actividad de la glutation S-transferasa en la flora gástrica. Este sistema enzimático es considerado como el principal destoxificante de ciertas sustancias químicas carcinogénicas (Lam et al., 1982).

Finalmente, los esteroles y tocoferoles se identifican tanto en la forma libre como esterificada, siendo los más abundantes: el sitosterol $(53-54 \%$ de la fracción total de esteroles) el stigmasterol (20-22\%) y el campesterol (18-19\%) (Itoh et al., 1973). Entre los tocoferoles destacan el $\alpha$-tocoferol y el $(\beta+\gamma)$-tocoferol, este último de gran interés por su mayor poder 
antioxidante. Además, tanto en el café arábica como en el robusta los $\beta$ y $\gamma$-tocoferoles se hallan en concentraciones de 2 a 3 veces superiores al $\alpha$-tocoferol (Folstar et al., 1977).

En lo que se refiere a la cera externa de los granos verdes de café, el $37 \%$ de ésta es soluble en éter de petróleo (Folstar et al., 1976), y su composición es muy parecida a la del aceite del café, con excepción de la composición en ácidos grasos y el menor contenido en hidratos de carbono. El $63 \%$ de la fracción restante, aparte de cafeína, contiene especialmente compuestos fenólicos.

\subsection{Composición química del grano tostado}

El café es probablemente uno de los alimentos que más se modifican durante su procesamiento lo que se refleja en cambios en sus características sensoriales. Por lo tanto, no sólo se producen cambios químicos sino también físicos, incluyendo los que obviamente afectan al color y al aumento de volumen del grano. Las principales modificaciones que se producen durante el tostado quedan recogidas en la Tabla II.

Tabla II

\section{Composición del extracto seco del café verde} $y$ tostado

\begin{tabular}{lcc}
\hline \multicolumn{1}{c}{ Constituyentes } & \% grano verde & \% grano tostado \\
\hline Hemicelulosas & 23.0 & 24.0 \\
Celulosa & 12.7 & 13.2 \\
Lignina & 5.6 & 5.8 \\
Grasas & 11.4 & 11.9 \\
Cenizas & 3.8 & 4.0 \\
Cafeína & 1.2 & 1.3 \\
Sacarosa & 7.3 & 0.3 \\
Acidos clorogénicos & 7.6 & 3.5 \\
Proteínas & 11.6 & 3.1 \\
Trigonelina & 1.1 & 0.7 \\
Azúcares reductores & 0.7 & 0.5 \\
Desconocido & 14.0 & 31.7 \\
Total & 100.0 & 100.0 \\
\hline
\end{tabular}

Adaptado de Encyclopedia of Food Science and Technology, Hui (1991)

Los compuestos mayoritarios solubles en agua del café verde que más se ven afectados por este procedimiento son las proteínas, sacarosa, ácidos clorogénicos y las cenizas. Durante el tostado del grano verde la cantidad total de azúcares disminuye. La mayor parte de la sacarosa desaparece en las primeras etapas del tostado, mientras que otros azú- cares simples, como glucosa, fructosa y arabinosa, se destruyen progresivamente (Kroplien, 1974).

Las pérdidas de cafeína, a pesar de lo que se podía esperar, son muy reducidas. Sin embargo, la trigonelina es rápidamente degradada durante el tostado, siendo del orden del $50-80 \%$, aunque se pueden alcanzar pérdidas superiores al incrementarse la conductividad térmica a través de las distintas capas del grano. Además, la trigonelina es un precursor del ácido nicotínico, formado por la pérdida progresiva de grupos metilos durante el tostado, el cual está presente sólo en el café tostado y debe ser considerado como una fuente importante de vitamina (Clarke y Macrae, 1989).

También se producen compuestos aromáticos nitrogenados, como la piridina. Sin embargo, las pirazinas, oxazoles y tiazoles, son también componentes del aroma del café, y proceden probablemente de la ruptura de las proteínas. Además, el tostado desnaturaliza las proteínas, las cuales constituyen un 10$12 \%$ del café verde y un $20-25 \%$ de la fracción soluble en agua fría. Durante dicho proceso los aminoácidos también se degradan o se combinan con otros componentes para dar una mezcla compleja de compuestos volátiles y no volátiles.

En cuanto a los ácidos clorogénicos, aparentemente modifican y controlan las reacciones que ocurren durante el tostado, y son de particular importancia en la descomposición de la sacarosa. Los triglicéridos, aportan el $7-16 \%$ de las grasas contenidas en el café, y contienen fundamentalmente los ácidos linoleico y palmítico, junto con otros formados a partir de los ácidos esteárico y oleico. Algunas fracciones de los glicéridos y parte del insaponificable se pierden durante el tostado, de forma que el contenido, tanto de aceite, como de ácidos grasos libres y fracción insaponificable, es inferior en la variedad robusta que en la arábica (Gariboldi, 1964, tomado de Hui, 1992).

\section{CAFÉ Y ENFERMEDAD CARDIOVASCULAR}

\subsection{Riesgo Cardiovascular y Tipos de Café}

Ya desde la década de los 70 se conocieron los primeros estudios que relacionaban el consumo de café y el aumento en los niveles plasmáticos de colesterol (Egede-Nissen 1970). Las observaciones del Tromso Heart Study (Thelle et al., 1983) mostraron que los consumidores de 5 a 8 tazas de café por día, presentaban $0.51 \mathrm{mmol} / /$ más de colesterol plasmáticos que los que tomaban menos de una taza de café diaria. Wei et al., (1995) en 2109 sujetos sanos, indicaron que el consumo de 1 taza de café por día producía cerca de $2 \mathrm{mg} / 100 \mathrm{dl}$ de incremento en el colesterol total del suero. 
Dentro de las sustancias del café que podían tener acción hipercolesterolemiante se estudió a la cafeína. Pero dicho efecto se descartó a raíz de los trabajos de Thelle (1995). Este autor indica que el café descafeinado aumenta los niveles plasmáticos de colesterol de forma similar al café con cafeína sin filtrar, aunque factores como la edad de los consumidores (generalmente ancianos) o el consumo de mayor cantidad de café puede producir resultados confusos. También según el mismo autor, ninguna publicación hasta aquel momento incriminaba a la cafeína como factor elevador del colesterol.

Superko et al., (1991) encontraron un incremento plasmático del colesterol-LDL en sujetos que consumían café descafeinado filtrado (obtenido del café robusta), mientras que el grupo que bebía café con cafeína (procedente de café arábica), no mostró ningún cambio significativo. Teniendo en cuenta estos resultados, Superko et al., (1991) plantean la hipótesis de que el café de la especie robusta (usualmente utilizado para preparar el café descafeinado) contiene un factor hipercolesterolemiante que no está presente en la especie arábica.

\subsection{Riesgo Cardiovascular y Formas de Preparación del Café}

Diversos estudios han mostrado relación entre el consumo de café hervido y el aumento de los niveles plasmáticos de colesterol-LDL. A este respecto, Bak y Grobee (1989), realizaron un estudio en 107 jóvenes sanos que fueron divididos en tres grupos: uno que se abstuvo de tomar café, otro que tomó café hervido y el tercero que ingirió café filtrado. A diferencia con los individuos que consumieron el café filtrado o con los que se abstuvieron del mismo, en los que no variaron virtualmente los niveles plasmáticos de colesterol total. En el grupo que bebió café hervido, se observó un aumento de $0.48 \mathrm{mmol} / \mathrm{l}$ del colesterol plasmático total al finalizar la novena semana del estudio. Sin embargo, los niveles plasmáticos de colesterol unido a las lipoproteínas de alta densidad (colesterol-HDL) y los niveles plasmáticos de apolipoproteínas A-I, A-II y B no cambiaron significativamente en los tres grupos. La concentración de colesterol-LDL se incrementó $0.39 \mathrm{mmol} / \mathrm{l}$ mientras que la de apolipoproteína B tendió a incrementarse de forma no significativa en los sujetos que ingirieron café hervido (Tabla III). Bak y Grobee (1989) llegaron a la conclusión que el consumo de café hervido en comparación con el consumo de café filtrado o con la abstención, produce después de 9 semanas alrededor de un $10 \%$ de aumento de en los niveles plasmáticos de colesterol total. Este incremento es completamente reversible, pues en la semana 21 , el colesterol plasmático había regresado a su valor nivel inicial, al suspender el consumo de café hervido.
Estos autores especularon sobre el mecanismo posible por el cual el café inducía el aumento del colesterol plasmático en los sujetos que consumían el café hervido, e indicaron que podía deberse a la diferencia de temperatura del proceso de preparación. Así, al preparar el café filtrado, la temperatura del agua es de $90-95^{\circ} \mathrm{C}$ cuando gotea en la cafetera eléctrica y en pocos segundos baja a $87.5^{\circ} \mathrm{C}$; después de tres minutos toda el agua ha goteado a través del papel filtro y la temperatura se mantiene en el recipiente aproximadamente a $85^{\circ} \mathrm{C}$. En cambio, generalmente en la preparación de la modalidad hervida, el café molido permanece expuesto por más tiempo al agua caliente, con lo que la extracción es más completa. También es posible, según indican estos mismos autores, que en el proceso de filtrado a través del papel filtro, las sustancias activas sean retenidas o filtradas selectivamente atendiendo al tamaño de partícula.

Los estudios de Aro et al., (1987) y Zock et al., (1990) han aportado la solución a estas hipótesis, señalando que el efecto hipercolesterolemiante del café es causado por los lípidos presentes en el café hervido $(0.1$ y $0.2 \mathrm{~g} / \mathrm{dl})$ y prácticamente ausentes en el café filtrado (cercanas a $0.001 \mathrm{~g} / \mathrm{dl})$. Así, Zock et al., (1990) estudiaron durante un período de 6 semanas el efecto del consumo de $80 \mathrm{~g} /$ día de sobrenadante de café hervido extraído por centrifugación en 10 sujetos sanos que habitualmente consumían 5 tazas de café por día y cuyos niveles basales de colesterol plasmático eran de $4,66 \mathrm{mmol} / \mathrm{l}$. A estos individuos se les ofreció, a cambio de las tazas de café un postre experimental en forma de natillas que contenía dicho sobrenadante. El consumo de esta fracción sobrenadante rica en lípidos $(1,3 \mathrm{~g})$ aumentó el colesterol total plasmático a $5,40 \mathrm{mmol} / \mathrm{l}$ en la tercera semana del estudio y a $5.72 \mathrm{mmol} / \mathrm{l}$ en la sexta semana. 11 semanas después de terminado el período de suplementación, el colesterol plasmático retornó a $4.59 \mathrm{mmol} / \mathrm{l}$. La media del aumento fue de $1.06 \mathrm{mmol} / \mathrm{l}(23 \%)$. También el colesterol-LDL se incrementó en $0.85 \mathrm{mmol} / \mathrm{l}(29 \%)$ y los triglicéridos totales aumentaron $0.51 \mathrm{mmol} / \mathrm{l}(55 \%)$, sin embargo los niveles de colesterol-HDL permanecieron constantes. Después de la prueba, las lipoproteínas séricas regresaron a sus valores basales (Tabla III).

Aro et al., (1987) señalaron que en sujetos que consumieron durante 4 semanas, 8 tazas de café hervido por día, el colesterol total en plasma aumentó $0.89 \mathrm{mmol} / \mathrm{l}$ en relación con los individuos que tomaban igual cantidad de café filtrado. Zock et al., (1990) resaltaron que sus datos eran comparables con los de Aro et al., (1987), pues las 8 tazas de café (casi un litro) proporcionaron $1.5 \mathrm{~g}$ de lípidos, mientras que, los $80 \mathrm{~g}$ de sobrenadante rico en lípidos proporcionaba $1.3 \mathrm{~g}$ de lípidos. En ambos estudios el aumento del colesterol plasmático fue de igual magnitud, no encontrándose efectos sobre los nive- 
les de colesterol-HDL. Dado que ese sobrenadante aportaba $109 \mathrm{mg}$ de cafeína por día, cabría la posibilidad de que tal cantidad influyera sobre los lípidos sanguíneos, pero se demostró que incluso cantidades superiores a $425 \mathrm{mg} /$ día de cafeína no afectaban a la lipemia. Zock et al., (1990) sugirieron que la fracción lipídica del café actuaba preferentemente sobre las VLDL, con aumento secundario del colesterol-LDL. Estos mismos autores indicaron que la sustancia responsable del efecto hipercolesterolemiante, se localizaba en el insaponificable de la fracción lipídica presente en el café hervido.

Tabla III

Resumen del diseño experimental y resultados de algunos estudios donde se relaciona consumo de café y modificación de lípidos y lipoproteínas séricas

\begin{tabular}{|c|c|c|c|c|c|c|c|c|c|}
\hline Referencia & Muestra & $\mathbf{N}$ & Duración & $\begin{array}{l}\text { Componente } \\
\text { estudiado }\end{array}$ & $\begin{array}{c}\text { Colesterol } \\
\text { Total (mmoll) }\end{array}$ & $\mathrm{LDL}$ (mmol/) & $\underset{\text { (mmol/) }}{\mathrm{HDL}}$ & $\begin{array}{l}\text { Triglicéridos } \\
\text { (mmol/) }\end{array}$ & $\begin{array}{c}\text { Apolipoproteina B } \\
(g / 1)\end{array}$ \\
\hline \multirow[t]{3}{*}{$\begin{array}{l}\text { Bak y Grobee } \\
\text { (1989) }\end{array}$} & $\begin{array}{l}\text { Sujetos } \\
\text { Sanos }\end{array}$ & 107 & 9 semanas & Placebo & Sin cambios & Sin cambios & Sin cambios & ND & Sin cambios \\
\hline & & & & Café Hervido & Sin cambios & Sin cambios & Sin cambios & ND & Sin cambios \\
\hline & & & & Café Filtrado & $\uparrow 0.48$ & $\uparrow 0.39$ & Sin cambios & ND & Sin cambios \\
\hline $\begin{array}{l}\text { Zoch et al., } \\
(1990)\end{array}$ & $\begin{array}{l}\text { Sujetos } \\
\text { Sanos }\end{array}$ & 10 & 6 semanas & $\begin{array}{l}80 \mathrm{~g} \text { de } \\
\text { sobrenadante }\end{array}$ & $\uparrow 1.06$ & $\uparrow 0.85$ & Sin cambios & $\uparrow 0.51$ & ND \\
\hline \multirow[t]{3}{*}{$\begin{array}{l}\text { van Rooij et al., } \\
\text { (1995) }\end{array}$} & $\begin{array}{l}\text { Sujetos } \\
\text { Sanos }\end{array}$ & 36 & 6 semanas & Aceite arábica & $\uparrow 1.14 \pm 0.97$ & $\uparrow 0.77 \pm 1.07$ & Sin cambios & $\uparrow 0.81 \pm 0.73$ & $\uparrow 0.35 \pm 0.26$ \\
\hline & & & & Aceite robusta & $\uparrow 0.52 \pm 0.62$ & $\uparrow 0.45 \pm 0.65$ & Sin cambios & $\uparrow 0.14 \pm 0.45$ & $\uparrow 0.17 \pm 0.21$ \\
\hline & & & & Placebo & $\uparrow 0.07 \pm 0.46$ & $\uparrow 0.11 \pm 0.29$ & Sin cambios & $\uparrow 0.06 \pm 0.34$ & $\uparrow 0.05 \pm 0.10$ \\
\hline \multirow[t]{3}{*}{$\begin{array}{l}\text { Weustwn-Vander } \\
\text { Wouw et al., } \\
\text { (1994) }\end{array}$} & $\begin{array}{l}\text { Sujetos } \\
\text { Sanos }\end{array}$ & 15 & 4 semanas & $\begin{array}{l}\text { Aceite de café } \\
\text { (arábica y robusta) } \\
\text { sin triglicéridos }\end{array}$ & $\uparrow 1.2$ & ND & Sin cambios & $\uparrow 0.74$ & ND \\
\hline & & & 4 semanas & $\begin{array}{l}\text { Aceite de café } \\
\text { sin diterpenos }\end{array}$ & Sin cambios & ND & Sin cambios & Sin cambios & ND \\
\hline & & & 6 semanas & $\begin{array}{l}\text { Cafestol y } \\
\text { kahweol puros }\end{array}$ & $\uparrow 1.7$ & ND & Sin cambios & $\uparrow 1.83$ & ND \\
\hline \multirow[t]{3}{*}{$\begin{array}{l}\text { Urgert et al., } \\
\text { (1995 b) }\end{array}$} & $\begin{array}{l}\text { Sujetos } \\
\text { Sanos }\end{array}$ & 15 & 3 semanas & $\begin{array}{l}\text { Café molido } \\
\text { con: cafestol } \\
39 \mathrm{mg} \\
\text { kahweol } 49 \mathrm{mg}\end{array}$ & $\uparrow 0.65 \pm 0.24$ & ND & ND & $\uparrow 0.30 \pm 0.32$ & ND \\
\hline & & & & $\begin{array}{l}\text { Café molido } \\
\text { fino con: } \\
48 \text { mg cafestol } \\
56 \text { mg kahweol }\end{array}$ & $\begin{array}{l}4.89 \pm 0.73 \\
\text { Valor final }\end{array}$ & ND & ND & $\begin{array}{l}1.31 \pm 0.54 \\
\text { Valor final }\end{array}$ & ND \\
\hline & & & & $\begin{array}{l}\text { Café molido } \\
\text { grueso con: } \\
37 \text { mg cafestol } \\
54 \text { mg kahweol }\end{array}$ & $\begin{array}{l}4.86 \pm 0.65 \\
\text { Valor final }\end{array}$ & ND & ND & $\begin{array}{l}1.01 \pm 0.45 \\
\text { Valor final }\end{array}$ & ND \\
\hline
\end{tabular}

$\uparrow:$ Aumento. ND: No determinado.

Según Fried et al., (1992), a pesar de lo concluyentes que parecen estos estudios, también presentaban algunas limitaciones que reducen en alguna medida la fiabilidad de las conclusiones. Así, en algunos casos se utilizó el té como bebida comparativa, no se guardaron períodos de descanso durante la intervención, el número de participantes no fue siempre estadísticamente representativo, siendo escasos los datos acerca del cumplimiento de los protocolos y de las variables de confusión. Fried et al., (1992) realizaron un estudio muy bien diseñado, en el que se respetaban todos los aspectos anteriormente mencionados, y demostraron que el consumo de café filtrado no modificaba la concentración en suero de colesterol-LDL respecto a la de los que to- maban té, pero incrementaba los niveles de colesterol-HDL respecto a los no consumidores de café.

Urgert et al., (1996), estudió la importancia de filtrar el café en un total de 46 hombres y mujeres sanos. En 22 sujetos que consumían diariamente de 5 a 6 tazas (0.9 litros) de café macerado en caliente ("de cafetière") encontraron después de un período de 24 semanas que el colesterol-LDL se elevaba entre un 9 y 14\%. Los restantes 24 individuos consumieron la misma cantidad de café, pero filtrado, encontrándose en ellos una elevación del colesterol sérico $0.26 \mathrm{mmol} / \mathrm{l}$ menor que en el caso del café macerado sin filtrar. El café moka y el expreso, contienen cantidades intermedias de diterpenos (Tabla IV) y se han asociado también con el aumento del nivel 
de colesterol (de 0.07 a $0.10 \mathrm{mmol} / \mathrm{l}$ ) en algunos estudios (Salvaggio et al., 1991; D’Avanzo et al., 1993).

\section{Tabla IV}

Cantidad de diterpenos en varias preparaciones de café y estimación del efecto predictivo en la elevación del colesterol sérico

\begin{tabular}{lccc}
\hline TIPO DE CAFÉ & $\begin{array}{c}\text { CAFESTOL } \\
\text { por taza } \\
\mathrm{mg}\end{array}$ & $\begin{array}{c}\text { KAHWEOL } \\
\text { por taza } \\
\mathrm{mg}\end{array}$ & $\begin{array}{c}\text { Estimación del aumento } \\
\text { de colesterol al consumir } \\
5 \text { tazas/dia } \\
\mathrm{mmol}\end{array}$ \\
\hline FILTRADO & 0.1 & 0.1 & 0.005 \\
PERCOLADOR & 0.1 & 0.1 & 0.005 \\
INSTANTÁNEO & 0.2 & 0.2 & 0.01 \\
MOKA & 1.1 & 1.4 & 0.07 \\
EXPRESO & 1.5 & 1.8 & 0.10 \\
HERVIDO & 3.0 & 3.9 & 0.19 \\
CAFETERA & 3.5 & 4.4 & 0.23 \\
TURCO/GRIEGO & 3.9 & 3.9 & 0.25 \\
\hline
\end{tabular}

Adaptado de: Seneca Investigadores (1996).

Con el fin de evaluar la influencia del método de preparación del café (expreso y moka) sobre el colesterol y lipoproteínas del suero, D'Amicis et al., (1996) realizaron un estudio en 84 varones adultos sanos italianos, consumidores habituales de café. La falta de efecto sobre los niveles de colesterol y lipoproteínas de estos dos tipos de preparación de café refuerza la hipótesis de que el método de preparación es un factor determinante en la asociación entre consumo de café y modificación del colesterol sanguíneo.

Recientemente, Urgert et al., (1997a) hallaron, que el consumo de café hervido se encontraba asociado con los niveles de $\mathrm{Lp}(\mathrm{a})$, partícula lipoproteica con un papel fundamental en el desarrollo de la enfermedad trombo-aterosclerótica. Se trataba de un estudio al azar, compuesto de cuatro ensayos controlados con diferentes tipos de ingestas. En todos los casos se produjo un descenso en los niveles de Lp (a) de diferente magnitud, por lo que se consideró que los diterpenos del café tienen una función moduladora sobre la $\mathrm{Lp}(\mathrm{a})$.

\subsubsection{Cafestol y Kahweol}

En los granos de café se encuentran de forma natural y en cantidades relativamente importantes dos diterpenos: cafestol y kahweol. Estas dos sustancias se encuentran en mayor concentración en el café hervido, por lo que se han señalado como responsables de incrementar el colesterol plasmático (Weusten van der Wouw, 1994, Heckers et al., 1994, van Rooij et al., 1995). En cambio, el café filtrado, el café instantáneo y el café percolado, contienen can- tidades insignificantes de cafestol y kahweol, por lo que carecen o no afectan de forma relevante a los niveles de colesterol sérico (Tabla IV). Estas conclusiones han llevado a recomendar que personas con riesgo de enfermedad coronaria seleccionen para su consumo preparaciones de café pobres en diterpenos (Urgert et al., 1995a, Urgert y Katan, 1996 y Urgert et al., 1996). Urget et al., (1995a) indicaban que el tiempo de preparación de las infusiones tiene poco efecto sobre el contenido de diterpenos en estos tipos de café, pero en las preparaciones ufuertes" tipo hervido, express francés y expresso, se produjo un aumento de los diterpenos, no encontrándose dicho incremento en el café tipo turco/griego. (Urgert et al., 1995a).

Según Urget et al., (1997b) las mujeres, en relación a los varones, modifican en menor cuantía los lípidos plasmáticos cuando ingieren los diterpenos del café. Además, este efecto hipercolesterolemiante de los diterpenos, no parece producirse con la misma intensidad en todas las especies animales estudiadas. Terpstra et al., (1995) señalaron que contrariamente a los resultados obtenidos en humanos, el aceite de café no afectaba en primates no humanos los niveles plasmáticos de colesterol o de triglicéridos, sugiriendo que los efectos negativos de los diterpenos del aceite de café, presentes en el café hervido, parecen específicos sólo para los humanos. Beynen et al., (1996) encontraron que hamsters y ratas no respondieron de la forma esperada con aumentos del colesterol sérico al café hervido sin filtrar, y concluyeron que tales animales no eran modelos adecuados para la investigación de los efectos hipercolesterolémicos del café.

En el estudio de van Rooij et al., (1995) se analizaron los efectos sobre la colesterolemia de estos dos diterpenos contenidos en los aceites de café arábica y robusta. Estos aceites fueron extraídos de los granos verdes de ambas variedades de café y se administraron en forma de emulsión a 36 sujetos sanos en la cantidad de $7,5 \mathrm{ml}$ de emulsión homogeneizada ( $1 \mathrm{~g}$ de aceite de café), dos veces al día. Como placebo se utilizó aceite de cacahuete. Después de 6 semanas de tratamiento, el incremento en los niveles plasmáticos de colesterol total fue de $0.52 \pm 0.62 \mathrm{mmol} / \mathrm{l}$ para el aceite del café robusta, $y$ casi el doble para el aceite arábica $(1.14 \pm 0.97$ $\mathrm{mmol} / \mathrm{l})$, lo que significó un aumento del $20.1 \%$. El incremento en el grupo placebo no fue significativo (Tabla III). Este aumento se debió principalmente a la elevación del colesterol-LDL, particularmente en el grupo del café arábica con un $0.77 \pm 1.07 \mathrm{mmol} / \mathrm{I}$ en relación al $0.45 \pm 0.65 \mathrm{mmol} / \mathrm{l}$ del robusta, pero debido a las dispersión de los resultados no existieron diferencias significativas en el colesterol transportado por esta fracción lipoproteica entre los tres grupos. Además, la concentración de apolipoproteína $B$ y de triglicéridos séricos se elevó en $0.35 \pm 0.28 \mathrm{~g} / \mathrm{l}$ 
y $0.81 \pm 0.65 \mathrm{mmol} / /$, repectivamente después de administración del aceite de café arábica. En los grupos que recibieron aceite de café robusta y placebo, las modificaciones de apolipoproteína $B$ y triglicéridos fueron insignificantes. No existieron efectos sobre el colesterol-HDL en ninguno de los tres tratamientos.

Los efectos sobre el colesterol y la apolipoproteína B del estudio de van Rooij (1995) son comparables a los obtenidos por Kark et al., (1985), Forde et al., (1985) y van Dusseldorp et al., (1991) con café hervido, o a los de Zock et al., (1990) y Weusten-van der Wouw et al., (1994) con el extracto de la fracción lipídica del café.

La concentración de ambos diterpenos, y particularmente de kahweol es muy superior en el aceite del café arábica que en el de café robusta (Tabla V). El efecto más intenso del aceite de café arábica sobre los lípidos séricos que el del café robusta, justifica, por tanto, que se atribuyan fundamentalmente a los ésteres de ácidos grasos de kahweol los efectos hipercolesterolemiantes. Sin embargo, debido al diferente contenido de cafestol de los mismos (Tabla V), los efectos de los ésteres de cafestol sobre el colesterol plasmático también han sido estudiados. Van Rooij et al., (1995), consideraron que tanto uno como otro diterpeno tenían el potencial suficiente como para producir incremento del colesterol plasmático, en contraposición a lo expresado por otros autores que encuentran que el cafestol es el principal componente responsable de este efecto. De los efectos comparados de cafestol y kahweol sobre la colesterolemia nos encargaremos a continuación.

Tabla V

\section{Contenido $(\mathrm{g} / \mathrm{kg})$ de alcoholes diterpénicos y esterificados de aceites de café}

\begin{tabular}{lcc}
\hline & ARABICA & ROBUSTA \\
\cline { 2 - 3 } Esteres de ácidos grasos de Kahweol & 85 & 1 \\
Esteres de ácidos grasos de Cafestol & 68 & 29 \\
Kahweol libre & 2 & ND \\
Cafestol libre & 2 & 1 \\
Ester de Cafestol-metil palmitato & ND & 9 \\
\hline
\end{tabular}

ND: No determinado. Adaptado de van Rooij y col. (1995).

La investigación de Weusten-van der Wouw et al., (1994) es clave en la búsqueda del factor presente en las fracciones de aceite de café, que provoca este aumento del colesterol plasmático. En dicho estudio, 15 voluntarios ingirieron durante cuatro semanas $0.75 \mathrm{~g} /$ día de una fracción de aceite de café libre de triglicéridos, pero conteniendo cafestol y kahweol, y en ellos se produjo un aumento de colesterol plasmático en relación con el del grupo control de 48 $\mathrm{mg} / \mathrm{dl}(1.2 \mathrm{mmol} / \mathrm{l})$. Por el contrario, en otro grupo de voluntarios, un aceite de café libre de triglicéridos y sin cafestol ni kahweol, no produjo efecto alguno sobre la colesterolemia. Para un tercer grupo de tres voluntarios, el consumo de $73 \mathrm{mg} /$ día de cafestol puro y $58 \mathrm{mg} /$ día de kahweol incrementó después de 6 semanas el colesterol plasmático en $66 \mathrm{mg} / \mathrm{dl}(1.7$ $\mathrm{mmol} / \mathrm{l}$ ) (Tabla III). El aceite de café robusta, que contenía cafestol y una insignificante cantidad de kahweol (Tabla IV) también elevó el colesterol. Weusten-van der Wouw et al., (1994) concluyeron que por cada $2 \mathrm{mg}$ de cafestol consumido se producía un aumento de colesterol en plasma de $1 \mathrm{mg} / \mathrm{dl}$.

Urgert et al., (1997b) evaluaron el efecto del Kahweol sobre los lípidos séricos, comparando el efecto del cafestol puro con una mezcla de cafestol y kahweol, ya que era difícil obtener kahweol en cantidades suficientes como para estudiarlo de forma aislada. A una muestra de 10 varones sanos agrupados en parejas según la similitud de los niveles plasmáticos de colesterol, se realizó durante 28 días un estudio cruzado al azar. En el primer período de tratamiento 5 de los sujetos ingirieron 5 cápsulas/día que aportaban $64 \mathrm{mg}$ de cafestol y $1 \mathrm{mg}$ de kahweol, disuelto en $2 \mathrm{~g}$ de aceite placebo, mientras que los otros 5 tomaron cápsulas con $60 \mathrm{mg}$ de cafestol y 54 $\mathrm{mg}$ de kahweol, igualmente disuelto en dicho aceite. En un segundo período los tratamientos fueron intercambiados, para aportar dosis diferentes a las consumidas en la primera parte, ofreciéndose $61 \mathrm{mg}$ de cafestol puro a los individuos que ya habían ingerido cápsulas con ambos diterpenos y $60 \mathrm{mg}$ de cafestol con $48 \mathrm{mg}$ de kahweol, a los que tomaron las cápsulas con $64 \mathrm{mg}$ de cafestol y $1 \mathrm{mg}$ de kahweol.

En este último estudio el consumo del cafestol puro produjo un aumento de $17 \%$ de la concentración del colesterol sérico total $(0.79 \pm 0.14 \mathrm{mmol} / \mathrm{l})$, un incremento de un $19 \%$ en el colesterol-LDL $(0.57 \pm 0.13 \mathrm{mmol} / \mathrm{l}), \mathrm{y}$ también una elevación del $86 \%$ en los triglicéridos $(0.65 \pm 0.12 \mathrm{mmol} / \mathrm{l})$. La mezcla de los diterpenos indujo un aumento adicional de solamente un $2 \%$ para el colesterol total $(0.23 \pm 0.16 \mathrm{mmol} / \mathrm{l})$, un $4 \%$ en el colesterol-LDL $(0.23 \pm 0.16 \mathrm{mmol} / /)$ y un $7 \%(0.09 \pm 0.10 \mathrm{mmol} / \mathrm{l})$ en los triglicéridos. Se concluyó que el kahweol presentaba un menor efecto hiperlipidémico que el cafestol, ya que como es lógico pensar, si ambos diterpenos presentaran una actividad similar, el aumento obtenido con la mezcla debería haber sido cerca del doble que el aumento producido por el cafestol puro.

Hasta la fecha se desconoce a que se debe el distinto efecto hipercolesterolemiante de los dos diterpenos. Si bien kahweol y cafestol se diferencian estructuralmente en un doble enlace entre los carbonos 1 y 2 (Fig. 2), hecho que posiblemente permite una rápida biotransformación del kahweol para ser excretado con rapidez o para disminuir su capacidad hiperlipidémica (Urgert et al., 1996). 


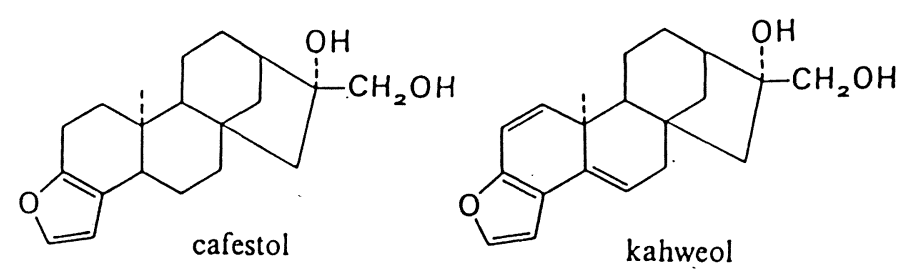

Figura 2

Estructura química del Cafestol y Kahweol

Los efectos del cafestol y kahweol también se han relacionado con su biodisponibilidad, la cual está a su vez condicionada por el tamaño de la molienda de los granos de café: molienda en grano fino o en grano grueso. A este respecto Urgert et al., (1995b) realizaron en dos grupos de 15 individuos sanos dos estudios complementarios. En el primer estudio se evaluó si la ingesta diaria de café molido elevaba el colesterol sérico. En el segundo se estudió la influencia de infusiones preparadas a partir de café molido fino o a partir de café molido en grano grueso sobre el colesterol sérico. Los resultados del primer estudio señalan que la ingestión durante 3 semanas de $8 \mathrm{~g}$ de café molido ( $39 \mathrm{mg}$ de cafestol y 49 $\mathrm{mg}$ de kahweol) aumentó significativamente el colesterol sérico en $0.65 \mathrm{mmol} / \mathrm{l}$ del colesterol sérico, lo que supone que por cada $2 \mathrm{mg}$ de cafestol ingerido aumenta el colesterol sérico en $0.03 \mathrm{mmol} / \mathrm{l}$ (Tabla III). En el segundo estudio se comparó el efecto del tamaño de las partículas sobre la disponibilidad del cafestol y el kahweol, ya que el café molido fino tenía $48 \mathrm{mg}$ de cafestol y $56 \mathrm{mg}$ de kahweol, mientras que el molido grueso contenía $37 \mathrm{mg}$ de cafestol y $54 \mathrm{mg}$ de kahweol (Tabla III). El aumento de colesterol sérico fue similar en ambos tratamientos, sin embargo se encontró que el cafestol afectaba en mayor medida a los triglicéridos que al colesterol plasmático.

La comparación de los datos de Urget et al., (1995b) con los de van Dusseldorp et al., (1991) señala que el efecto hiperlipemiante del cafestol y el kahweol del café molido y el de los diterpenos presentes en el café hervido o el del aceite de café fue similar. El nivel de cafestol y kahweol en las infusiones de café también se ha relacionado con el tipo de preparación de las mismas. Así, en preparaciones sin filtrar, como el macerado en caliente y el café turco/griego, las cantidades de cafestol y kahweol son similares a las halladas en el café hervido tipo escandinavo (Tabla IV). El consumo de este tipo de cafés eleva también los niveles de colesterol (Kark et al., 1985, IARC Working Group, 1991 y Urgert et al., 1995a, Séneca Investigadores, 1996).
Por último, dado que parece indiscutible que se incrementan el colesterol y el colesterol-LDL por el consumo de los diterpenos del café, sería interesante analizar si tales LDL son más aterogénicas (menor tamaño, menor relación colesterol-LDL/Apo B-LDL) y más o menos peroxidables que la de individuos que no consumen dichos diterpenos o lo hacen en menor cuantía.

\section{CONCLUSIONES}

A la vista de estos estudios puede concluirse que:

- La composición del café es compleja y depende del tipo y variedad empleada.

- La composición del café es altamente dependiente del tostado.

- El café descafeinado incrementa los niveles plasmáticos de colesterol, por lo que la cafeína no es responsable del efecto del café sobre este factor de riesgo cardiovascular.

- El café contiene lípidos que aumentan el colesterol plasmático.

- La fracción lipídica es retenida en la filtración en papel, por lo que el café filtrado no afecta, o lo hace en menor grado, los niveles de los lípidos plasmáticos.

- El café hervido sí aumenta los niveles de colesterol.

- En la mayoría de los estudios los niveles de colesterol-HDL prácticamente no varían.

- El cafestol y posiblemente el kahweol elevan los niveles de colesterol sérico.

- El aumento de los niveles plasmáticos inducidos por los lípidos del café revierten al cambiar el método de preparación o al suprimir el consumo de café.

Por último, creemos que entre otros aspectos sería necesario plantear estudios donde se analizara:

1.- El motivo de la especificidad de los efectos hipercolesterolemiantes de los diterpenos del aceite de café en los humanos y no en otras especies.

2.- La posible heterogeneidad de la respuesta hiperlipemiante de dichos diterpenos en diferentes sujetos y la causa responsable de dicha heterogeneidad.

3.- Las causas de la menor respuesta de los lípidos plasmáticos de las mujeres frente al consumo de los diterpenos del café.

4.- El efecto modulador de estos diterpenos sobre la peroxidación de las lipoproteínas LDL, HDL y Lp (a). 


\section{BIBLIOGRAFÍA}

Al Kahnal, M.L. (1997).— «Lipid analysis of Coffea arábica Linn. Beans and their possible hypercholesterolemic effects".-Int. J. Food Sci. Nutr., 48, 135-139.

Aro, A., Tuomilehto, J., Kostianien, E., Uusitalo U. y Pietinen P. (1987). - «Boiled coffee increases serum low density lipoprotein concentration".-Metabolism, 36, 1027-1030.

Bak, A. A. A. y Grobee, D. E. (1989).— «The effect on serum cholesterol levels of coffee brewed by altering or boiling".-N. Engl. J. Med., 321, 1432-1437.

Beynen, A.C., Weusten-Van Der Wouw, M.P.M.E., Roos, B. De y Katan, M. B. (1996).- -Boiled coffee fails to raise serum cholesterol in hamsters and rats".-Brit. J. Nutr., 76, 755-764.

Calzolari, C. y Cerma, E. (1963).- «Sulle Sostanze grasse del caffé».-Riv. Ital. Sostanze Grasse, 40, 176-180.

Carisano, A. y Gariboldi, L. (1964).- «Gas chromatographic examination of the fatty acids of coffe oil».-J. Sci. Food Agric., 15, 619-622.

Clarke, R.J. y Macrae, R. (Eds). (1989).- “Coffee».(Chemistry) Vol. 1, Elsevier applied Science.-London.

Clifford, M. N. (1975).- - The composition of green and roasted coffee beans".-Proc. Biochem., (4), 13-16, 19.

Clifford, M. N. (Eds.) (1985)._-“Coffee: Botany, Biochemistry and Production of Beans and Beverage".Croom-Helm, Ltd., London.

Clifford, M. N. y Willson, K. C. (Eds.) (1975)._- “Coffee: Botany, Biochemistry and Production of Beans and Beverage".-Croom-Helm, Ltd., Beckenham, Kent (UK).

Charrier, A. (1975).- - Variations in the caffeine content on coffee trees".-In: Seventh International Colloquium on the Chemistry of Coffee. Paris: Association Scientifique Internationale du Café (ASIC).

Charrier, A. y Berthaud, J. (1975).- - Variations in the caffeine content in the genus Coffea».-Café, Cacao, The, 19, 251-264.

Chassevent, F., Dalger, G., Cenwig, S. y Vincent, I.C. (1974)."Contribution to the study of Mascaracoffea. Study of lipid and unsaponificable fractions. Possible relationship between cafeine and chlorogenic acid contents".-Café, Cacao, The, 18, 49-56.

D'Amicis, A., Scaccini, C., Tomassi, G., Anaclerio, M. Stornelli, R. y Bernini, A. (1996)._- «talian Style Brewed Coffee: Effect on Serum Cholesterol in Young Men".-Interna. J. Epidemiol., 25, 513-519.

D'Avanzo, B., Santoro, L., Nobili, A., La Vecchia, C. y GISSIEFRIM Study Group (1993).-—Coffee Consumption and serum cholesterol".-Prev. Med., 22, 219-224.

Debry, G. (1994).- «Coffee and health».-John Libbey Eurotext, London.

De la Mota, I. (1991).- «El Libro del Café».-Ediciones Pirámide, S.A., Madrid. pp. 13-83.

Desrosier, N. W. (1987).- -Elementos de Tecnología de Alimentos".-S.A., Ed.-Compañía Editorial Continental, S.A., México.

Egede-Nissen, A. (1970).-«Kolesterol Kaffe».-En Observasjon fra praksis, 90, 1506-1507.

Folstar, P., Pilnik, W., de Heus, J.G. y van der Plas, H.C. (1976). - «The composition of the fatty acids in coffee oil and coffee wax».-In: Seventh International Colloquium on the Chemistry of coffee. Paris: Association Scientifique Internationale du Café (ASIC), 1976.

Folstar, P., van der Plas, H. C., Pilnik, W. y de Heus, J.G. (1977). - «Tocopherols in the unsaponifiable matter of coffee bean oil».-J. Agric. Food Chem., 25, 283-285.
Forde, O. H., Knutsen, S. F., Amesen E. y Thelle D. S. (1985)."The Tromso Heart Study: Coffee consumption and serum lipid concentrations in men with hypercholesterolemia: a randomized intervention study".-Br. Med. J., 290, 893-895.

Fried, R.E., Levine, D.M., Kwiterovich, P.O., Diamond, E. L., Wilder, L.B., Moy, T.F. y Pearson, T.A. (1992).— "The effect of filtered coffee consumption on plasma lipid levels".-JAMA, 267, 811-813.

Heckers, H., Gobel, U. y Kleppel, U. (1994)._ —End of the coffee mystery: diterpene alcohols raises serum low-density lipoprotein cholesterol and triglyceride levels".-J. Intern. Med., 235, 192-193.

Hui, Y.H. Editor (1992).- - Encyclopedia of Food Science and Technology". Vol. 1, 441-447.-A Whilwy Interscience Publication, New York.

larc Working Group (1991)._-«IARC Monographs on the evaluation of the carcinogenic risk to humans" en "Coffee, tea, mate, methylxanthines and methylyoxal" Vol 51. International Agency for Research on Cancer, Lyon, France.

Innis, S.M., Dyer, W.J., Quinian, P. y Diersen-Chade, D. (1995).- «Palmitic acid is absorbed as sn-2 monopalmitin from milk and formula with rearranged triacylglycerols and results in increased plasma triglyceride sn-2 cholesteryl ester palmitate in piglets".-J. Nutr., 125, 73-81.

Itoh, T., Tamura, T. y Matsumoto, T. (1973).— «Methylsterol compositions of 19 vegetable oils".-J. Am. Oil Chem. Soc., 50, 300-303.

Kark, J. D., Friedlander, Y., Kaufmann, N. A. y Stein, Y. (1985).— -Coffe, tea, and plasma cholesterol: The Jerusalem Lipid Research Clinic Prevalence Study».-Br. Med. J., 291, 699-704.

Kaufmann, H. P. y Hamsagar, R. S. (1962a).- «Zur kenntnis der lipoide der kaffeebohne I: Über fettsäure ester des cafestols».-Fette, Seiffen Anstr. Mittel» 64, 206-213.

Kaufmann, H. P. y Hamsagar, R. S. (1962b).- -Zur kenntnis der lipoide der kaffeebohne II: Die veränderung der lipoide bei der kaffeeröstung".-Fette, Seiffen Anstr. Mittel, 64, 734-738.

Kaufmann, H. P. y Schickel, R. (1963)._- «ur kenntnis der lipoide der kaffeebohne III: ie eindarstellung des kahweols".-Fette Seiffen Anstr. Mittel, 65, 529-532.

Kaufmann, H. P.,y Sen Gupta, A. K.(1963).- «Zur kenntnis der lipoide der kaffeebohne IV: Weittere untersuchungen über das verhalten der lipoide bei der kaffee-röstung".-Fette, Seiffen Anstr. Mittel, 65, 1012-1016.

Kaufmann, H. P. y Sen Gupta, A. K. (1964).- «Zur kenntnis der lipoide der kaffeebohne V: Die triterpene und kohlenwosserstoffe».-Fette Seiffen Anstr. Mittel, 66, 461- 466.

Kroplien, U. (1974)._ «Monosacharides in roasted and instant coffees".-J. Agric. Fd. Chem., 22, 110-115.

Lam, L. K. T., Spaarnins, V. L. y Watterberg, L. W. (1982)._- «solation and identification of kahweol palmitate and cafestol palmitate and active constituents of green coffee beans that enhance glutathione S-transferase activity in the mouse".-Cancer Res., 42, 1193-1198.

Maier, H. G. (1981).-«Kaffee».-Paul Parey Ed., Berlin, Verlag, 18, p. 199.

Poisson, J. (1977).- «Chemical and biological aspects of the composition of green coffee».- In: Eigth International Scientific Colloquium on Coffee. Paris: Association Internationale du Café (ASIC), pp. 33-57. 
Renaud, S.C., Ruf, J.C., y Petithory, D. (1995).- «The positional distribution of fatty acids in palm oil lard influences their biologic effects in rats".-J. Nutr., 125, 229-237.

Roffi, J., do Santos, A.C., Mexia, J.T., Bussan, F. y Maigrot, M. (1971).- «Green and roasted Angolan coffees. A chemical study".- - In: Fifth International Colloquium on the Chemistry of Coffee. Cinquiéme Colloque Internationale sur la Chimie des Cafés Verts, Torréfiés et leurs Dérivés, Lisbonne, 14-19, Juin 1971, pp. 179-200.

Salvaggio, A., Periti, M., Miano, L., Quaglia, G. y Marzorati, D., (1991).- "Coffee and cholesterol, an Italian Study".-Am. J. Epidemiol., 134, 149-156.

Seneca Investigators (1996).—-Consumption of unfiltered coffee brews in elderly Europeans".-Eur. J. Clin. Nutr., 50 (suppl. 2), S101-S104.

Stefanucci, A., Clinton, W. P. y Hannell, M. (1979)."Encyclopedia of chemical Technology".-Vol. 6, p. 511-522. $3^{\mathrm{a}}$ ed.-John Wiley An Son, Inc., New York.

Streuli, H. (1973).- - The present state of coffee chemistry".- In: Sixth International Scientific Colloquium on the Chemistry of Coffee. Sixiéme Colloque International sur la Chimie des Cafés Verts, torréfiés et leurs Dérivés, pp. 61-72.

Superko, H. R., Bortz, W. Jr., Williams, P. T., Albers, J. J. y Wood, P. W. (1991).- -Caffeinated and decaffeinated coffee effects on plasma lipoprotein cholesterol, apolipoproteins, and lipase activity: a controlled, randomized trial".-Am. J. Clin. Nutr., 54, 599-605.

Terpstra, A.H.M., Katan, M.B., Weusten-van der Wouw, M.P.M.E., Nicolosi, R.J. y Beynen, A.C. (1995)."Coffee oil consumption does not affect serum cholesterol in rhesus and cebus monkeys".-J. Nutr., $125,2301-2306$

Thelle, D. S. (1995).- «Coffee, tea and coronary heart disease".-Curr. Opin. Lipidol., 6, 25-27.

Thelle, D. S., Arnesen, E. y Forde, O.H. (1983).- «The Tromso Heart Study. Does coffee raise serum cholesterol?".-N. Engl. J. Med., 300, 1454-1457.

Urgert, R. y Katan, M. B. (1996)._ «The cholesterol-raising factor from coffee beans".-J. Roy. Soc. Med., 89, 618-623.

Urgert, R., Weusten-van der Wouw, M.P.M.E., Hovenier, R., Meyboon, S., Beynen, A.C. y Katan, M. B. (1997a).- «Diterpenes from coffee beans decrease serum levels of lipoprotein $L p(a)$ in humans: results from four randomised controlled trials».-Eur. J. Clin. Nutr., 51, 431-436.

Urgert, R., Essed, N., Weg, G. Van Der, Kosmeijer-Schuil, T. G. y Katan, M. B. (1997b). - «Separate effects of the coffee diterpenes cafestol and kahweol on serum lipids and liver aminotransferases».-Am. J. Clin. Nutr., 65, 519-524.

Urgert, R., Meyboom, S., Kuilman, M., Rexwinkel, H., Vissers, M. N., Klerrk, M. y Katan, M. B. (1996).-
"Comparison of effect of cafetiére and filtered coffee on serum concentrations of liver aminotransferases and lipids: six month randomised controlled trial». $-\mathrm{Br}$. Med. J. (Clinical research edition), 313, 1362-1366.

Urgert, R., Schulz, A.G. M., Katan, M. B. (1995b).«Effects of cafestol and Kahweol from coffee grounds on serum lipids and serum liver enzymes in humans".-Am. J. Clin. Nut., 61, 149-154.

Urgert, R., Van der Weg, G., Kosmeijer-Schuil, G., Van der Bovenkamp, P., Hovenier, R. y Katan, M. B. (1995a)."Levels of the cholesterol-elevating diterpenes cafestol and kahweol in various coffee brews".- J. Agr. Food Chem., 43, 2167-2172.

Van Dusseldorp, M., Katan, M. B., Van Uliet, T., Demacker, P.N.M. y Stalenhoef, A.F.H. (1991).- «Cholesterolraising factor boiled coffee does not pass a paper filter.-Atheroscler Thromb., 11, 586-593.

Van Rooij, J., Van Der Stegen, C., Schoemaker, R. C., Kroon, C., Burggraaf J., Hollaar, L., Vroon, T. F. F. P., Smelt, A. H. M. y Cohen, A. F. (1995).— -A placebocontrolled parallel study of the effect of two types of coffee oil on serum lipids and transaminases: Identification of chemical substances involved in the cholesterol-raising effect of coffee".-Am. J. Clin. Nutr., 61, 1277-1283.

Vitzthum, O.G. (1975).- «Kaffee und Coffein».-Eichler, O., Ed., Springer-Verlag, Berlín, pp. 3-77.

Wajda, P. y Walczk, D. (1978).— «Relationship between acid value of extracted fatty matter and age of green coffee beans".-J. Sci. Food Agric., 29, 377-380.

Wei, M., Macera, C.A., Hornung, C.A. y Blair, S. N. (1995)."The impact of changes in coffee consumption on serum cholesterol».-J. Clin. Epidemiol., 48, 1189-1196.

Weusten-van de Wouw, M.P.M.E., Katan, M.B., Viani, R., Huggelt, A.C., Liardon, R., Lund-Larsen, P.G., Thelle, D.S., Ahola, I., Aro, A., Meyboon, S. y Beynen, A.C. (1994). - «Identity of the cholesterol-raising factor from boiled coffee and its effects on liver function enzymes".-J. Lipid. Res., 35, 721-733.

Xábregas, J., Gomes, V., do Santos, A.C., Nogueira, C., Gonçalves, A., y Mexia, T. (1971).— «Analysis of some characteristics of Angolan green coffees".-In: Fifth International Scientific Colloquium on the Chemistry of Green and Roasted Coffees and their Derivatives, Lisbon, 14-19 June, 1971, pp. 27-44.

Zock, P.L., Katan, M.B., Merkus, M.P., Van Dusseldorp, M. y Harryran, J.L. (1990).— —Effect of a lipid-rich fraction from boiled coffee on serum cholesterol».-Lancet. $335,1235-1237$. 